\title{
Low Energy
} Ion Assisted Film Growth

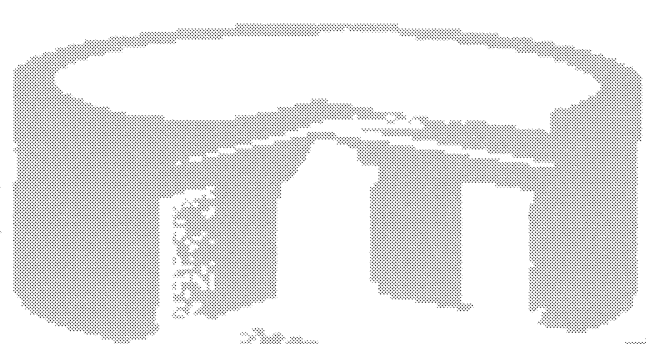


This page is intentionally left blank 
Low Energy Ion Assisted Film Growth

\section{A R González-Elipe F Yubero}

Instituto de Cienca de Materiales de Sevilla (CSIC-Uni. Sevilla), Spain

\section{J M Sanz}

Universidad Autónoma de Madrid, Spain 


\section{Published by}

Imperial College Press

57 Shelton Street

Covent Garden

London WC2H 9HE

\section{Distributed by}

World Scientific Publishing Co. Pte. Ltd.

5 Toh Tuck Link, Singapore 596224

USA office: Suite 202, 1060 Main Street, River Edge, NJ 07661

UK office: 57 Shelton Street, Covent Garden, London WC2H 9HE

\section{British Library Cataloguing-in-Publication Data}

A catalogue record for this book is available from the British Library.

\section{LOW ENERGY ION ASSISTED FILM GROWTH}

Copyright $\odot 2003$ by Imperial College Press

All rights reserved. This book, or parts thereof, may not be reproduced in any form or by any means, electronic or mechanical, including photocopying, recording or any information storage and retrieval system now known or to be invented, without written permission from the Publisher.

For photocopying of material in this volume, please pay a copying fee through the Copyright Clearance Center, Inc., 222 Rosewood Drive, Danvers, MA 01923, USA. In this case permission to photocopy is not required from the publisher.

ISBN $\quad 1-86094-351-9$ 


\section{Contents}

Foreword

xiii

\section{CHAPTER 1: BASIC CONCEPTS ON THE INTERACTION OF LOW ENERGY ION BEAMS WITH SOLID TARGETS}

1.1. Introduction

1.2. Interatomic interaction .........................................................................

1.2.1. Atoms in condensed matter.......................................................... $\quad 3$

1.2.2. Interaction of energetic ions with condensed matter: Interatomic potential ............................................................ 6

1.2.3. Power law approximations to the interatomic potential ............... 10

1.3. Basic concepts in classical dynamics of binary elastic collisions ................ $\quad 12$

1.3.1. Ion energy loss rate ................................................................ 14

1.3.1.1. Nuclear stopping ....................................................... 16

1.3.1.2. Electronic stopping ................................................. 19

1.4. Range of energetic ions in solids .......................................................... 20

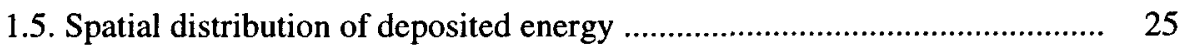

1.6. Damage induced by ion bombardment .................................................... 27

1.6.1. Primary knock-on atoms formation ............................................ 27

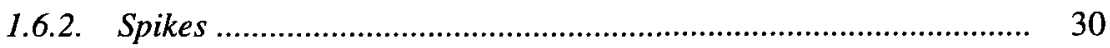

1.6.3. Thermal spikes.................................................................. 32

1.6.4. Density of the deposited energy................................................. $\quad 33$

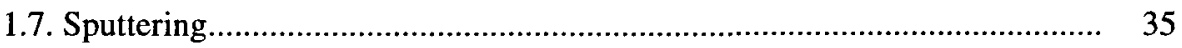

1.7.1. Sputtering yield ................................................................... 36

1.7.2. Angular distribution of sputtered atoms ....................................... 38

1.7.3. Energy distribution of the sputtered atoms ................................... 39 
1.8. Experimental parameters in IAD thin film growth ......................................... 40

1.8.1. The ion to atom arrival ratio and the normalized energy 41 concept.

1.8.2. Ion momentum transfer ........................................................... 44

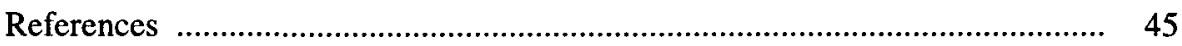

\section{CHAPTER 2: ION ASSISTED METHODS OF PREPARATION} OF THIN FILMS

2.1. Assistance of film growth with independent ion sources ............................. 47

2.1.1. Evaporation and ion bombardment of the growing film ............... $\quad 49$

2.1.2. Laser ablation and ion bombardment of the growing film ............. 52

2.1.3. Dual ion beam deposition of thin films (DIBS) ............................ 55

2.1.4. Ion beam induced chemical vapour deposition (IBICVD) ............ 58

2.2. Ion assisted deposition of thin films without independent ion

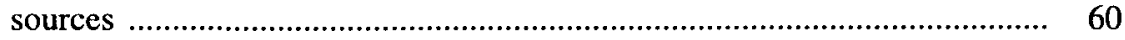

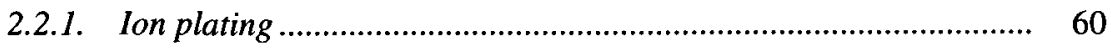

2.2.2. Ionised magnetron sputtering (IMS) .......................................... 64

2.2.3. Filtered vacuum arc deposition (FVAD) ...................................... 66

2.2.4. Ionised cluster beam (ICB) ..................................................... 69

2.2.5. Mass selected ion beam deposition (MSIBD) ................................. 72

2.3. Plasma immersion ion implantation ......................................................... 75

2.3.1. Plasma immersion ion implantation (PIII) ................................. 76

2.3.2. Plasma immersion ion deposition (PIID) ..................................... 78

2.4. Broad beam ion sources ......................................................................... 80

2.4.1. Kaufmann type ion sources ...................................................... 81

2.4.2. End-Hall ion sources................................................................. 83

2.4.3. Filament-less ion sources .......................................................... 85

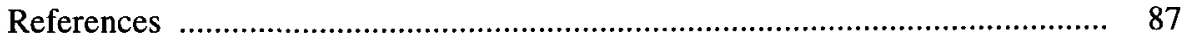


CHAPTER 3: EFFECTS INDUCED BY THE ION ASSISTANCE OF FILM GROWTH

3.1. Ion beam effects during film growth

3.2. Nucleation and growth of thin films under ion bombardment

3.2.1. Nucleation and growth of physical vapour deposited (PVD) thin films

3.2.2. Effects of ion bombardment on nucleation

3.2.3. Monitoring the surface defects and nucleation processes induced by ion bombardment.

3.2.4. Description of Nucleation and Growth processes by analysis of STM/AFM images

3.3. Topography and surface and interface roughness

3.3.1. Grain size

3.3.2. Surface roughness ............................................................... 100

3.3.3. Step and surface coverage .................................................. 103

3.3.4. Surface roughness of thin films grown by $I B D$.......................... 103

3.3.5. Interface roughness ............................................................. 104

3.3.6. Monitoring the interface roughness by $X$-ray reflectometry......... 106

3.3.7. Epitaxial growth of thin films ......................................... 108

3.4. Interface mixing ........................................................................ 108

3.4.1. Mixing in thick films and bulk materials induced by high energy ions....................................................................... 109

3.4.2. Interface mixing in IAD thin films ...................................... 110

3.4.3. Monitoring interface mixing by TEM/EELS ........................ 111

3.5. Densification of thin films .............................................................. 113

3.5.1. Columnar growth in PVD thin films ..................................... 113

3.5.2. Densification in IAD thin films ............................................. 114

3.5.3. Evolution of density and crystallinity with ion energy and I/A ratio

3.6. Defect generation

3.6.1. Formation of defects in IAD thin films ...................................... 119

3.6.2. Surface and bulk defects as a function of beam energy ............... 120 
3.6.3. Defects and control of the microstructure of thin films by annealing treatments

3.6.4. Inert gas incorporation .................................................... 123

3.7. Amorphisation, crystallinity and phase transformations ........................... 125

3.7.1. Amorphisation in IAD thin films ........................................... 126

3.7.2. Effect of temperature on crystallisation ..................................... 126

3.7.3. Amorphisation and phase transformation phenomena. Stabilisation of unstable phases .................................................... 128

3.7.4. Monitoring the degree of amorphisation in IAD thin films .......... 128

3.8. Compound formation by IAD ...................................................... 130

3.8.1. Control of stoichiometry in IAD thin films ............................ 131

3.8.2. Metastable phases of nitride thin films .................................. 133

3.9. Texture development .................................................................. 137

3.9.1. Monitoring the texture in IAD thin films by XRD: Basic 137 definitions

3.9.2. Texture in PVD thin films ................................................... 142

3.9.3. Texture evolution in IAD thin films and process parameters ........ 143

3.9.4. Models for texture development .............................................. 147

3.9.5. Biaxial orientation ................................................................. 150

3.9.6. Applications of textured thin films...................................... 153

3.10. Influence of ion assistance on thin film stress ................................... 154

3.10.1. Basic concepts on stress ................................................... 154

3.10.2. Distribution of stress between substrate and thin film ................ 154

3.10.3. Thermal stress in thin films .................................................... 156

3.10.4. Intrinsic stress in PVD thin films.......................................... 156

3.10.5. The stress in IAD thin films: Dependence on experimental parameters...................................................................... 158

3.10.6. Compressive stress in IAD thin films.................................... 161

3.10.7. The stress in IAD thin films: Models ................................. 162

3.11. Improvement of adhesion in IAD thin films .................................. 165

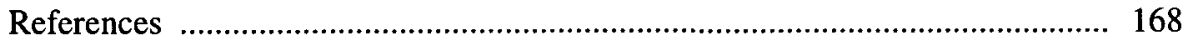




\section{CHAPTER 4: APPLICATIONS OF IAD PROCESSING}

4.1. Tribological coatings .............................................................................. 174

4.1.1. Hard and wear resistant coatings ............................................ 175

4.1.2. Solid lubricant coatings .......................................................... 177

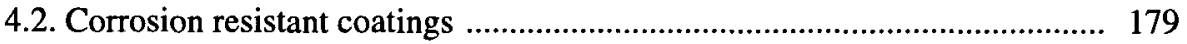

4.2.1. Metal coatings ......................................................................... 181

4.2.2. Oxide and nitride coatings ....................................................... 182

4.2.3. Corrosion protection of magnesium alloys .................................... 183

4.2.4. Zinc and zinc alloys................................................................... 184

4.3. Modification of biomaterials ................................................................... 185

4.3.1. Fretting wear and damage .................................................... 185

4.3.2. Corrosion protective coatings ................................................... 186

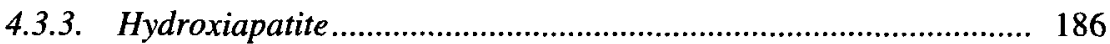

4.3.4. Biocompatibility ....................................................................... 187

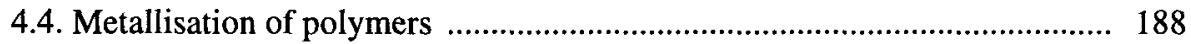

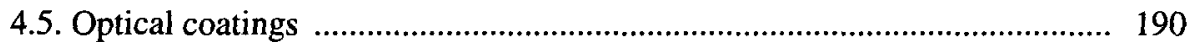

4.5.1. Dielectric oxide films............................................................ 191

4.5.2. Fluoride thin films .................................................................. 196

4.5.3. Narrow band filters ................................................................ 197

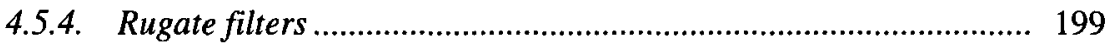

4.5.5. Transparent conducting films................................................... 201

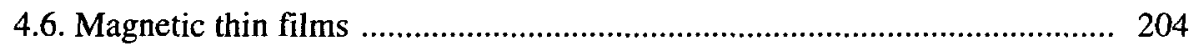

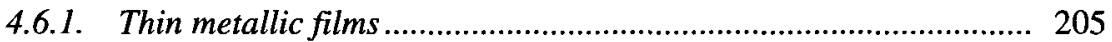

4.6.2. Magnetoresistive materials ....................................................... 206

4.6.3. Reading/ writing magnetic heads .............................................. 208

4.6.4. Hard bias magnetic thin films ................................................. 209 


\section{CHAPTER 5: DIAMOND-LIKE CARBON AND CUBIC-BORON NITRIDE FILMS}

5.1. Diamond-like carbon

5.2. Characterization methods and related properties

5.2.1. Hydrogen concentration 220

5.2.2. Atomic structure (electron and neutron scattering) 220

5.2.3. $s p^{3} / s p^{2}$ bonding fraction (Raman, NMR, EELS/XAS) 221

5.2.4. Density 224

5.2.5. Cross sectional structure and in-depth composition (TEM, EELS).

5.3. DLC deposition methods 228

5.4. Influence of the deposition parameters on the $\mathrm{sp}^{3}$ bonding fraction and related properties 231

5.4.1. Influence of the ion energy. 231

5.4.2. Influence of the substrate temperature 234

5.4.3. Influence of other deposition parameter. 238

5.5. Stress in DLC films 239

5.6. Properties and applications of the DLC films 240

5.6.1. Mechanical and tribological properties 242

5.6.2. Optical and electronic properties 243

5.7. Cubic Boron nitride films 245

5.8. Characterization of c-BN 245

5.8.1. Stoichiometry 246

5.8.2. XRD diffraction. 246

5.8.3. Phase identification by FTIR spectroscopy and EELS/XAS 247

5.8.4. Microstructure by TEM 250

5.9. c-BN deposition methods 251

5.10. Influence of the deposition parameters 252 
5.12. Properties and applications of c-BN films ............................................. 257

5.12.1. Tribological properties .............................................................. 257

5.12.2. Optical and electrical properties .................................................. 258

5.13. Modelling the growth of $\mathrm{sp}^{3}$ bonded materials (ta-C, ta-C:H and

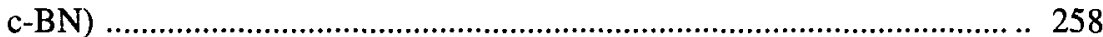

5.13.1. The preferential sputtering model................................................. 260

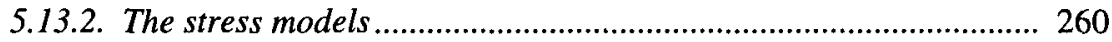

5.13.3. Models involving a thermal spike mechanism ............................... 261

5.13.4. Subplantation models.................................................................. 262

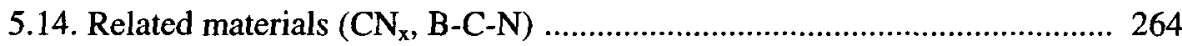

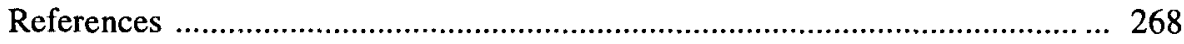

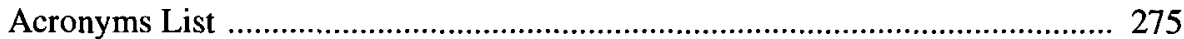

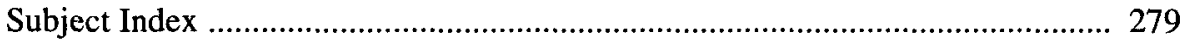


This page is intentionally left blank 


\section{Foreword}

This book deals with the use of accelerated ion beams to assist the growth of thin films. It was recognised as early as the seventies that the bombardment of a growing film with a beam of accelerated ions induces significant changes in its properties and that these changes have many potential applications. The term "Ion beam assisted deposition" (IBAD) and the more general one "Ion assisted deposition" (IAD) were coined to characterise all the procedures of preparation of thin films that, in one way or another, use this type of approach. Since then, the modalities of this technology and its applications, in very different scientific and industrial areas, have expanded to constitute what is now a mature technique, useful for a tailored synthesis of thin films.

Within a general perspective, several books and reviews have dealt with the phenomena involved during the IAD of thin films. Itoh's book of 1989 and some review papers by Smidt (1990), Hirvonen (1991) and Ensinger (1994, 1995, 1997) are noted examples of such publications. This literature covers the advances made during the seventies and eighties in the development of IAD techniques. Much research effort has contributed to new developments and to a more thorough understanding of the basic phenomena involved during IAD of thin films, not only providing an empirical perspective on the effects of ion bombardment on thin film properties, but permitting a clear interpretation of these phenomena on an atomistic scale. The present book aims to provide a comprehensive description of the basic phenomena involved in IAD processes, the different techniques of preparation of thin films that can be considered as ion assisted methods, and some of the applications of the prepared thin films in different fields of science and technology. Throughout this presentation, emphasis is put on results which appeared in scientific literature during the last decade, given that the most important contributions made before are properly discussed in these previous publications.

This book is written with the intention that it serve as an introductory manual for researchers, post-graduates and engineers from industry with little or no experience in IAD thin films. Nonetheless, some basic principles of the interaction 
of ions with solid targets are also reviewed with the intention of providing a good scientific basis that will permit a sound and justified presentation of results and phenomena. In this respect, it is hoped that the book will also serve to provide researchers active in this scientific area with a general scheme and practical ideas for the improvement of their investigation in this interesting field of material science and technology.

The book is divided into five chapters dealing with, respectively, the basic principles of the interaction of accelerated ions with matter; a description of the different techniques relying on the IAD concept; the changes experienced by the thin films when subjected to ion bombardment; some applications of the IAD thin films in different fields of science and technology and a description of the major issues related with two sets of materials for whose synthesis the use of IAD procedures is essential (i.e., c-BN and diamond and related materials). Whenever possible, results by updated methods of characterisation of thin films are included as examples of the possibilities of the IAD procedures. In some cases, this presentation of experimental results is accompanied by a brief presentation of the technique, so that non-experts will also be able to understand the main message of the proposed case.

We hope that the reader will find this manuscript interesting and, what would be even more satisfactory for the authors, useful for their own investigations.

Finally, we would like to thank José A. Rodriguez for his good job preparing the drawings of the different deposition methods included in Chapter 2, and the support provided by the author's research institutions (i.e., CSIC, Universidad de Sevilla and Universidad Autónoma of Madrid).

Seville and Madrid May 2002 